\title{
Synthesis and characterization of heat-resistant and soluble poly(amide-imide)s from unsymmetrical dicarboxylic acid containing 2-(triphenyl phosphoranylidene) moiety and various aromatic diamines
}

\author{
SEEMA AGRAWAL and ANUDEEP KUMAR NARULA* \\ University School of Basic and Applied Sciences, Guru Gobind Singh Indraprastha University, Sector-16C \\ Dwarka, Delhi 110078, India \\ e-mail: researchchemlabb58@gmail.com
}

MS received 29 August 2014; revised 29 November 2014; accepted 30 November 2014

\begin{abstract}
An unsymmetrical and non-coplaner heterocyclic phosphorus containing dicarboxylic acid monomer, (DCA-3) is successfully synthesized with high purity. A series of novel aromatic poly(amide-imide)s having ether or/sulphur or/fluorine or/phosphorus containing phenyl moieties in their backbone are then prepared via a direct phosphorylation polycondensation of synthesized dicarboxylic acid with various aromatic diamines. Chemical structures of DCA-3 as well as resulting polymers are confirmed by FT-IR, NMR spectroscopic techniques and elemental analysis. These polymers are readily soluble in a variety of aprotic polar solvents such as NMP, DMSO, DMAc and DMF, etc. UV spectra showed that all poy(amide-imide)s films exhibit high optical transparency. In addition, the glass transition temperatures $\left(\mathrm{T}_{\mathrm{g}}\right)$ of these polymers were determined by differential scanning calorimetry and found in the range $271-346^{\circ} \mathrm{C}$. Furthermore, thermogravimetric analysis of these polymers showed good thermal stability, $10 \%$ weight loss at temperature in excess of $538^{\circ} \mathrm{C}$ and char yield at $700^{\circ} \mathrm{C}$ in nitrogen ranging from 68 to $79 \%$. From wide-angle X-ray diffraction experiments, all polymers showed amorphous behaviour.
\end{abstract}

Keywords. Poly(amide-imide)s; pendent phosphorus; thermal stability; optical transparency; solubility.

\section{Introduction}

Aromatic polyimides are well known as high performance polymers which possess outstanding thermal stability, chemical resistance and excellent mechanical and electrical properties as well as low flammability. ${ }^{1-6}$ However, some applications of polyimides are limited due to their poor solubility in common organic solvents, high glass transition temperature and high processing temperature, which are due to molecular stiffness and high level intermolecular packing of this polymeric system. In order to overcome these limitations, various synthetic efforts have been exercised in order to improve processability of polyimides without sacrificing the above mentioned excellent properties. It is observed that the incorporation of flexible linkage or pendent groups or molecular symmetry can impart many of these desirable properties to the polymers, making them suitable for a much wider range of applications..$^{7-15}$ However, the problem of processability of polyimides is still a big problem and

*For correspondence there is a need of further improvement. It has been demonstrated that the insertion of amide groups in imide containing macromolecular chains can enhance the organo-solubility and thermal stability. Among others, heterocycles are interesting chemical structures to modify the properties of aramides and thermally stable polymers because they usually impart excellent thermal stability with improved solubility and decrease the $\mathrm{T}_{\mathrm{g}}$ of materials. As a consequence, research on aromatic polyimides with heterocycles in the main chain is widespread in scientific literature. ${ }^{16-20}$ The incorporation of thermally stable groups such as aromatic or heterocyclic rings into polymer main chain is an effective approach to improve the thermal properties of polymers. The combination of above effective factors i.e., incorporation of heteroaromatic rings, pendent substituent and flexible linkages, with each other may be proposed as suitable choice for increasing the processability of aromatic polymers without extreme loss of thermal resistance. ${ }^{21-23}$ On the other hand, depending upon applications, optical transparency of polymer films is of special importance, such as oriented films in liquid crystal display devices, flexible solar radiation 
protectors and optical half wave plates for light wave circuits. ${ }^{24-28}$

Specifically, the introduction of ether, sulphur, fluorine and phosphorus in the backbone of polymer provides an increase in the polarity of the chain due to the difference of electronegativity among $\mathrm{O}, \mathrm{P}, \mathrm{S}, \mathrm{F}$ and $\mathrm{C}$. This fact results in a higher thermal stability of the resulting polymers and is also a successful route to improve the solubility. Since then, fluorinecontaining diamines and dianhydrides have been introduced to prepare fluorinated polyimides with properties of low water uptake, low reflective index and low dielectric constant. ${ }^{29}$ Fluorine is also known to enhance the solubility of polyimides even in chloroform, toluene and tetrahydrofuran. According to the phosphorylation technique first described by Yamazaki et al., ${ }^{30}$ a series of novel organosoluble poly(amide-imide)s with laterally attached ether or S or P or F containing phenyl groups are synthesized from the new phosphorus based dicarboxylic acid and various diamines. On the other hand, presence of $\mathrm{P}$ in polymeric chain improves the thermal stability and organo-solubility as well as flame retardancy of polymers. ${ }^{31,32}$

\section{Experimental}

\subsection{Materials}

Diphenyl isopropyl phosphine, triphenyl phosphine oxide, 4,4'- oxydiphthalic anhydride (ODPA), 2,2-bis (4-aminophenyl)-1,1,1,3,3,3-hexafluoropropane (BAF), 4,4'-diaminodiphenyl ether (DDE) and 2-(triphenyl phosphoranylidene) succinic anhydride all were purchased from Sigma Aldrich and used as received. L-tryptophan, 4,4'-diaminodiphenyl sulphone (DDS) and glacial acetic acid are purchased from Merck and used without any purification. Pyridine $(\mathrm{CDH})$ was purified by distillation under reduced pressure over calcium hydride. Triphenyl phosphite (TPP, Merck) was used as received. Anhydrous calcium chloride was dried under reduced pressure at $150^{\circ} \mathrm{C}$ for $6 \mathrm{~h}$ prior to use. Nmethyl-2-pyrrolidone (NMP, Sigma Aldrich) was dried over phosphorus pentoxide for at least $15 \mathrm{~h}$ and distilled under reduced pressure. Methanol (Fisher Scientific) was received as HPLC grade solvent and used without purification. Ethanol and Palladium on Activated Carbon $(\mathrm{Pd} / \mathrm{C})$ were purchased from Sigma Aldrich and used as received. Bis (3-aminophenyl) isopropyl phosphine (BAP) and tris (3-aminophenyl) phosphine oxide (TAPO) were synthesized by nitration of diphenyl isopropyl phosphine and triphenyl phosphine oxide followed by reduction with $\mathrm{Pd} / \mathrm{C}$ and hydrazine hydrate according to the procedure reported in literature. ${ }^{33}$ Structures of all diamines are shown below:

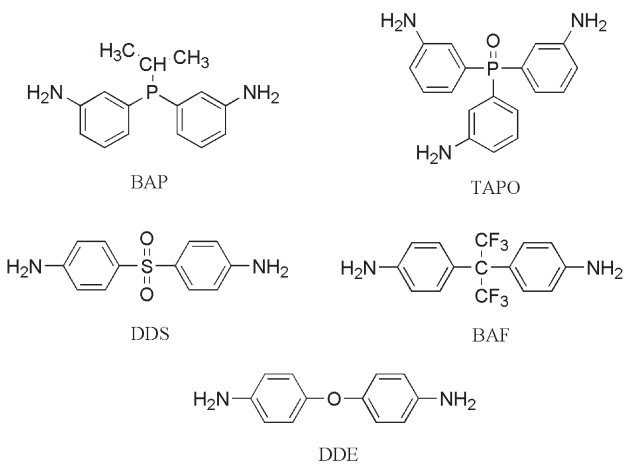

\subsection{Measurements}

FT-IR spectra were recorded on Perkin Elmer RXI spectrophotometer in the range $4000-400 \mathrm{~cm}^{-1}$. Elemental analysis wwes carried out by using $\mathrm{GmbH}$ VarioEL CHNS elemental analyser. NMR spectra are recorded on a BRUKER TOP-SPIN $300 \mathrm{MHz}$ spectrophotometer using DMSO- $d_{6}$ as a solvent and tetramethyl silane as an internal reference at room temperature. The inherent viscosities of the polymers were measured with an Ubbelohde viscometer at $30^{\circ} \mathrm{C}$. UVvisible spectra of the polymer films and the dilute $\mathrm{N}, \mathrm{N}$-dimethylformamide solution were recorded on Shimadzu UV-1601 UV-visible spectrophotometer. Differential scanning calorimetry (DSC) of the polymers was performed on TA 2100 thermal analyser having DSC 910 module with the heating rate of $10^{\circ} \mathrm{C} / \mathrm{min}$ in nitrogen atmosphere. Thermogravimetric data were obtained on a Perkin Elmer Diamond model at a heating rate of $10^{\circ} \mathrm{C} / \mathrm{min}$ in nitrogen. X-ray diffraction patterns of the polymers are obtained at room temperature on a Bruker Model D-8 Advance diffractometer with a scanning speed of $4^{\circ} / \mathrm{min}$, and recorded in the $2 \theta$ range of $5^{\circ}-40^{\circ}$. Weight-average $\left(M_{w}\right)$, Number-average $\left(M_{n}\right)$ molecular weights and polydispersity index $\left(M_{w} / M_{n}\right)$ were determined by gel permeation chromatography (GPC). Four Waters Ultrastyragel columns were used for GPC analysis with tetrahydrofuran (THF) $\left(1 \mathrm{~mL} \mathrm{~min}^{-1}\right)$ as the eluent. The eluents were monitored with a differential refractometer detector. The molecular weight calibration was carried out using polystyrene standards.

\subsection{Monomer synthesis}

2.3a Synthesis of phosphorus containing diamine (DA-1): DA-1 was prepared according to scheme 1 . 2-(Triphenyl phosphoranylidene) succinic anhydride $(0.026 \mathrm{~mol})$ was dissolved in glacial acetic acid $(25 \mathrm{~mL})$ 


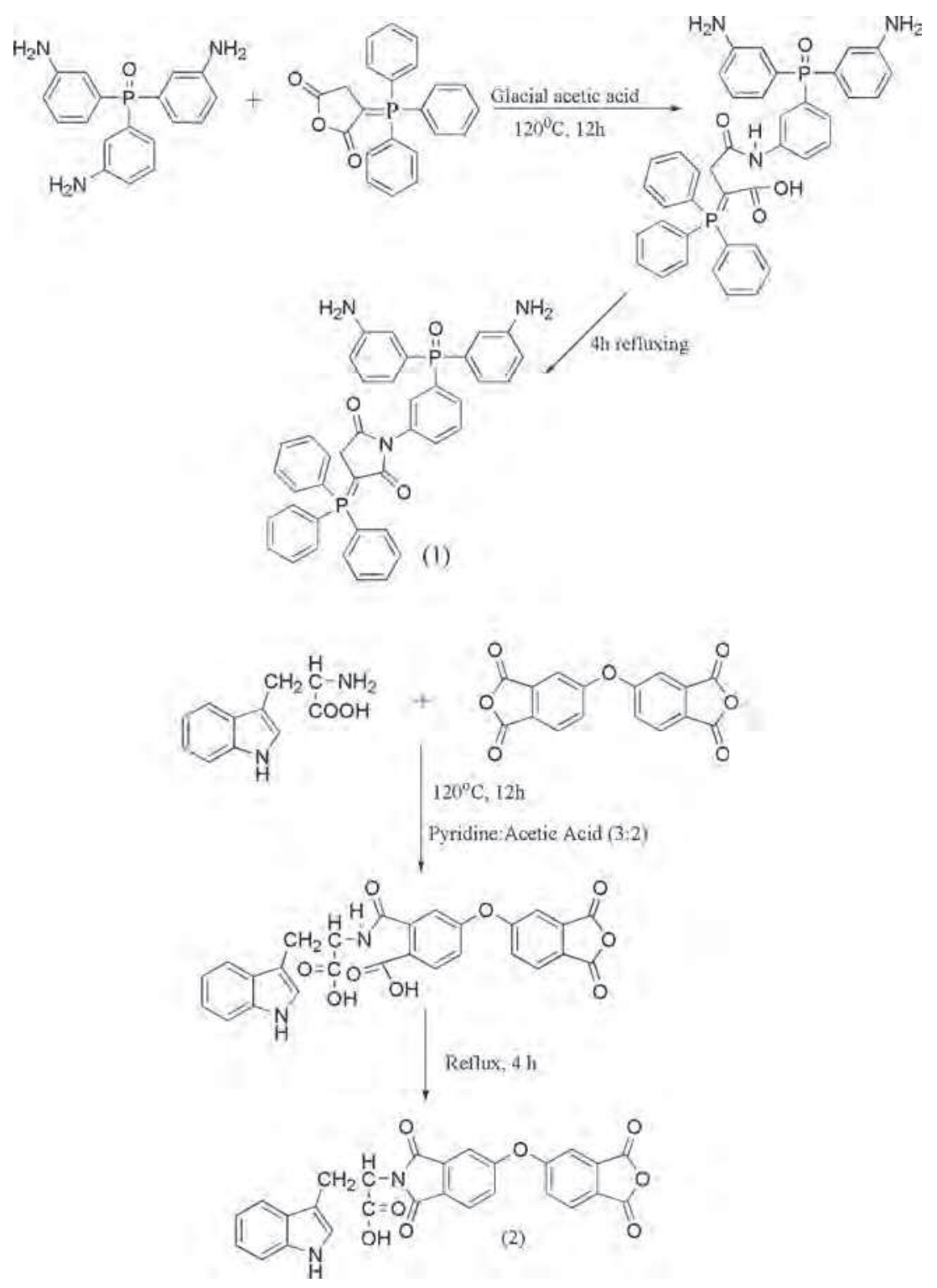

Scheme 1. Synthesis of phosphorus containing diamine and monoanhydride.

and TAPO $(0.026 \mathrm{~mol})$ is added. The solution was stirred for $12 \mathrm{~h}$ and then refluxed for $4 \mathrm{~h}$, the resulting mixture precipitated in ice cold water $(100 \mathrm{~mL})$, to give brown coloured solid. The precipitate was initially washed with water and then with aqueous sodium bicarbonate solution to remove acid content. The synthesized solid was dried in vacuum at $7^{\circ} \mathrm{C}$ for 5-6 $\mathrm{h}$ and recrystallized with chloroform to give pure compound.

2.3b Synthesis of monoanhydride (MA-2): Into a $100 \mathrm{~mL}$ round-bottom flask, ODPA $(0.031 \mathrm{~mol}), \mathrm{L}-$ tryptophan $(0.031 \mathrm{~mol})$, a mixture of acetic acid and pyridine $(3: 2)(75 \mathrm{~mL})$ and a stirring bar were placed. The mixture was stirred at room temperature for overnight and then refluxed for $4 \mathrm{~h}$. The solvent was removed under reduced pressure and the residue as dissolved in cold water $(100 \mathrm{~mL})$, then the solution is decanted and conc. $\mathrm{HCl}(7 \mathrm{~mL})$ was added. A cream colour precipitate was formed, filtered off and dried, to give approximately 97\% yield. The synthesis of MA-2 is shown in scheme 1 .

2.3c Synthesis of dicarboxylic acid (DCA-3): A $250 \mathrm{~mL}$ round bottom flask equipped with magnetic stirrer and reflux condenser was charged with phosphorus containing DA-1 (0.014 mol), synthesized monoanhydride, MA-2 $(0.028 \mathrm{~mol})$ and glacial acetic acid $(40 \mathrm{~mL})$ according to scheme 2 . The resulting heterogeneous solution was refluxed for $14 \mathrm{~h}$. It was filtered to give approximately $93.2 \%$ yield of pale yellow solid. The crude was rinsed with ethanol to remove acetic acid and 


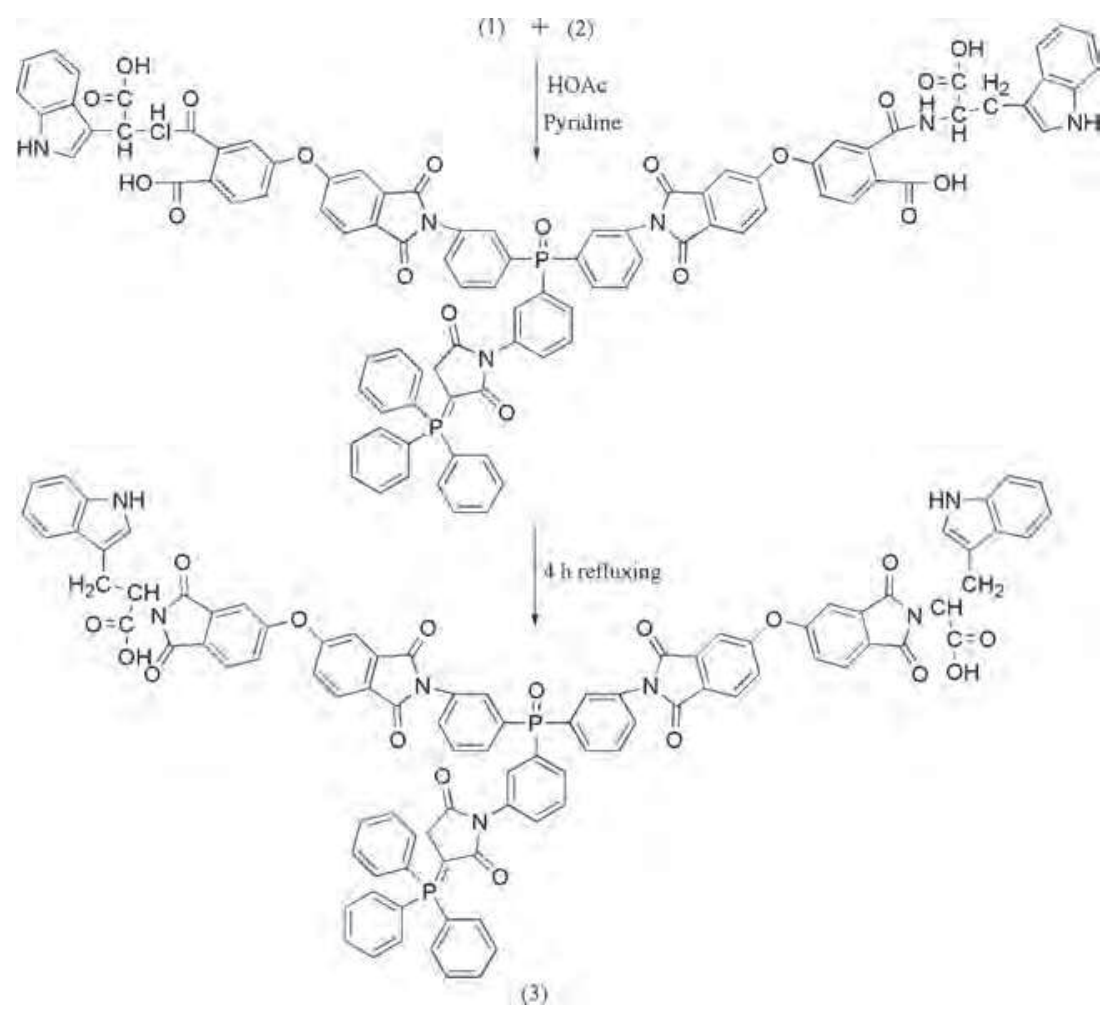

Scheme 2. Synthesis of dicarboxylic acid (3).

dried in vacuum at $85^{\circ} \mathrm{C}$ for overnight. The product was recrystallized with $\mathrm{DMF} / \mathrm{H}_{2} \mathrm{O}(1: 1)$.

\subsection{Polymer synthesis}

A typical example of TPP-activated polycondensation of polymer synthesis is shown in scheme 3 and described as follows. A mixture of DCA-3 $(1 \mathrm{mmol})$ and aromatic amine $(1 \mathrm{mmol})$, dried $\mathrm{CaCl}_{2}(0.30 \mathrm{~g})$, TPP $(2.1 \mathrm{~mL})$ and pyridine $(2.1 \mathrm{~mL})$ in NMP $(14 \mathrm{~mL})$ was stirred at $110^{\circ} \mathrm{C}$ for $4 \mathrm{~h}$ in a $25 \mathrm{~mL}$ flask. The viscosity of the reaction solution is increased after $1 \mathrm{~h}$ and an additional volume of NMP is added to carry out the reaction in homogeneous medium. At the end of the reaction, the polymer solution was poured slowly into $250 \mathrm{~mL}$ of stirring methanol, to give a fibre-like precipitate which is washed thoroughly with hot water and methanol, filtered and dried in vacuum at $120^{\circ} \mathrm{C}$.

All the poly(amide-imide)s were synthesized by a similar procedure.

\section{Results and Discussion}

\subsection{Monomer synthesis and characterization}

As shown in schemes 1 and 2, the phosphorus containing target compound DCA-3 is synthesized by refluxing of intermediate compounds i.e., DA-1 and MA-2. All synthesized compounds are characterized by elemental analysis, FT-IR and NMR spectroscopic techniques. Table 1 shows physical characterization and elemental analysis data of all compounds. Figure 1 displays the FT-IR and ${ }^{1} \mathrm{H}-\mathrm{NMR}$ spectra of DA-1. Figure 1 (top), shows IR spectrum of DA-1. In this spectrum, $\mathrm{P}=\mathrm{O}$ stretching absorption appears at $1195 \mathrm{~cm}^{-1}$, while N-H stretching absorption at $3353 \mathrm{~cm}^{-1}$. In addition, an amide $\mathrm{C}=\mathrm{O}$ stretching absorption peak is observed at $1682 \mathrm{~cm}^{-1}$ and a peak due to P-Ar at 1418 $\mathrm{cm}^{-1}$. The ${ }^{1} \mathrm{H}-\mathrm{NMR}$ spectrum of compound DA-1 is shown in figure 1 (bottom), in which the protons for the amine groups are observed at $3.97 \mathrm{ppm}$ in form of broad and short peak. In this spectrum, all aromatic protons resonate in the region 6.15-7.42 ppm, which are easily attributable and compatible with the proposed structure. In figure 2 (top), the ${ }^{1} \mathrm{H}-\mathrm{NMR}$ spectrum of MA-2 presents aromatic signals in the range of 6.83$8.27 \mathrm{ppm}$ and a short peak at $11.25 \mathrm{ppm}$ due to proton of carboxylic group. Figure 2 (bottom), shows the ${ }^{13} \mathrm{C}$ NMR spectrum of MA-2. In this spectrum, carbons of carboxylic acid and anhydride group were observed at 165.1 and $156.8 \mathrm{ppm}$.

A typical ${ }^{1} \mathrm{H}-\mathrm{NMR}$ spectrum of DCA-3 is shown in figure 3. This spectrum shows the signal at 10.93 ppm which corresponds to the carboxylic group, in addition to a sharp signal at $10.31 \mathrm{ppm}$ due to $\mathrm{N}-\mathrm{H}$ 


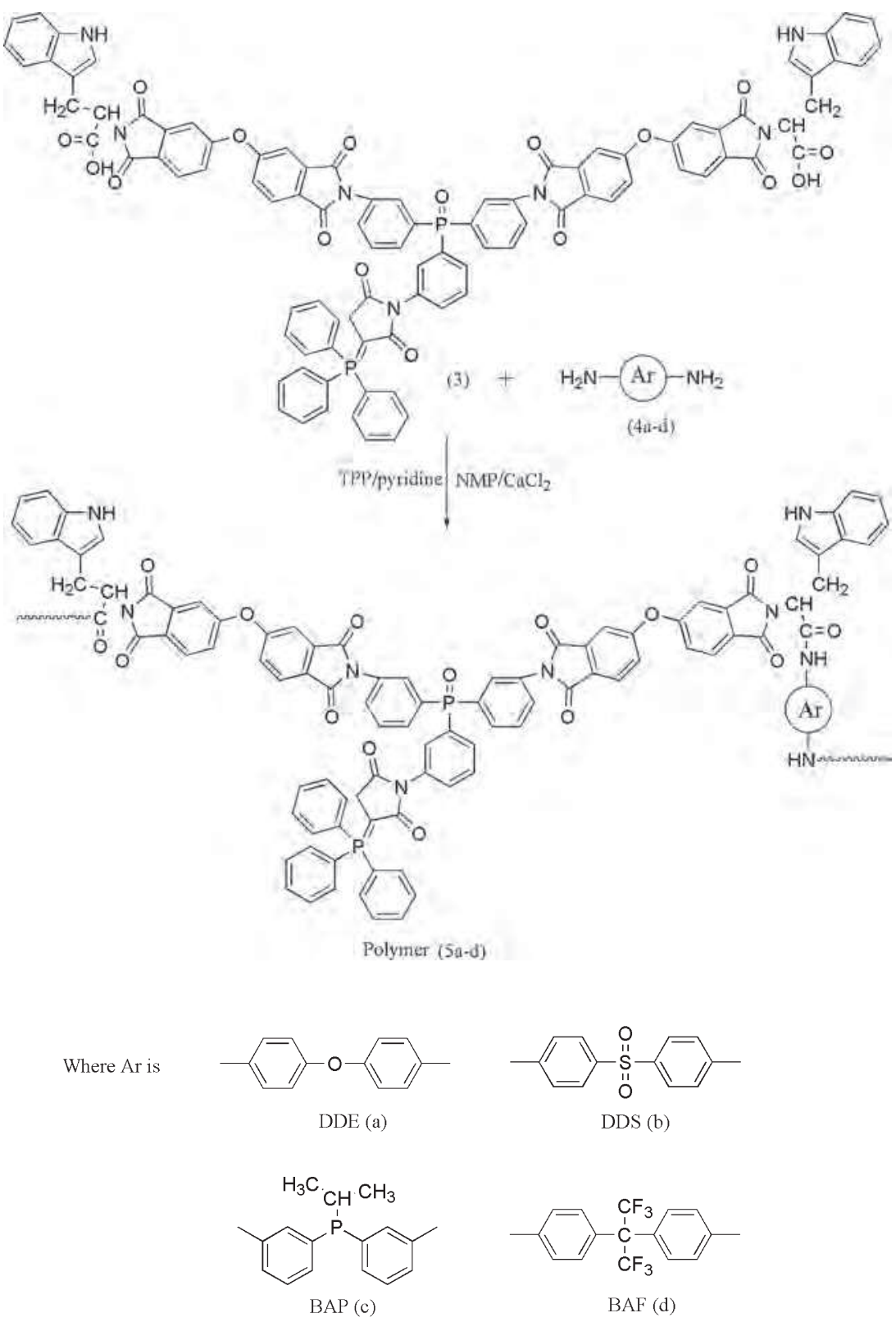

Scheme 3. Synthesis of poly(amide-imide)s.

proton of pyrrole ring. Table 2 displays spectral data of all intermediate and target compounds.

Above characterizations confirm that the target product was synthesized successfully.

\subsection{Polymer synthesis and characterization}

The direct polycondensation of DCA-3 with different aromatic diamines is carried out using a mixture

Table 1. Physical characteristics and elemental analysis data of intermediate compounds and monomer.

\begin{tabular}{|c|c|c|c|c|c|c|c|}
\hline Monomer & Yield (\%) & Colour & Molecular Formula & & $\% \mathrm{C}$ & $\% \mathrm{H}$ & $\% \mathrm{~N}$ \\
\hline \multirow[t]{2}{*}{ DA-1 } & \multirow[t]{2}{*}{99.2} & \multirow[t]{2}{*}{ Brown } & \multirow[t]{2}{*}{$\mathrm{C}_{40} \mathrm{H}_{33} \mathrm{~N}_{3} \mathrm{O}_{3} \mathrm{P}_{2}$} & Calcd. & 72.17 & 5.00 & 6.31 \\
\hline & & & & Found & 72.67 & 4.55 & 6.67 \\
\hline \multirow[t]{2}{*}{ MA-2 } & \multirow[t]{2}{*}{97.1} & \multirow[t]{2}{*}{ Pale brown } & \multirow{2}{*}{$\mathrm{C}_{27} \mathrm{H}_{16} \mathrm{~N}_{2} \mathrm{O}_{8}$} & Calcd. & 65.32 & 3.25 & 5.64 \\
\hline & & & & Found & 64.89 & 3.06 & 5.51 \\
\hline \multirow[t]{2}{*}{ DCA-3 } & \multirow[t]{2}{*}{93.2} & \multirow{2}{*}{ Light yellow } & \multirow[t]{2}{*}{$\mathrm{C}_{99} \mathrm{H}_{61} \mathrm{~N}_{7} \mathrm{O}_{17} \mathrm{P}_{2}$} & Calcd. & 69.59 & 3.79 & 6.04 \\
\hline & & & & Found & 69.14 & 3.54 & 6.49 \\
\hline
\end{tabular}



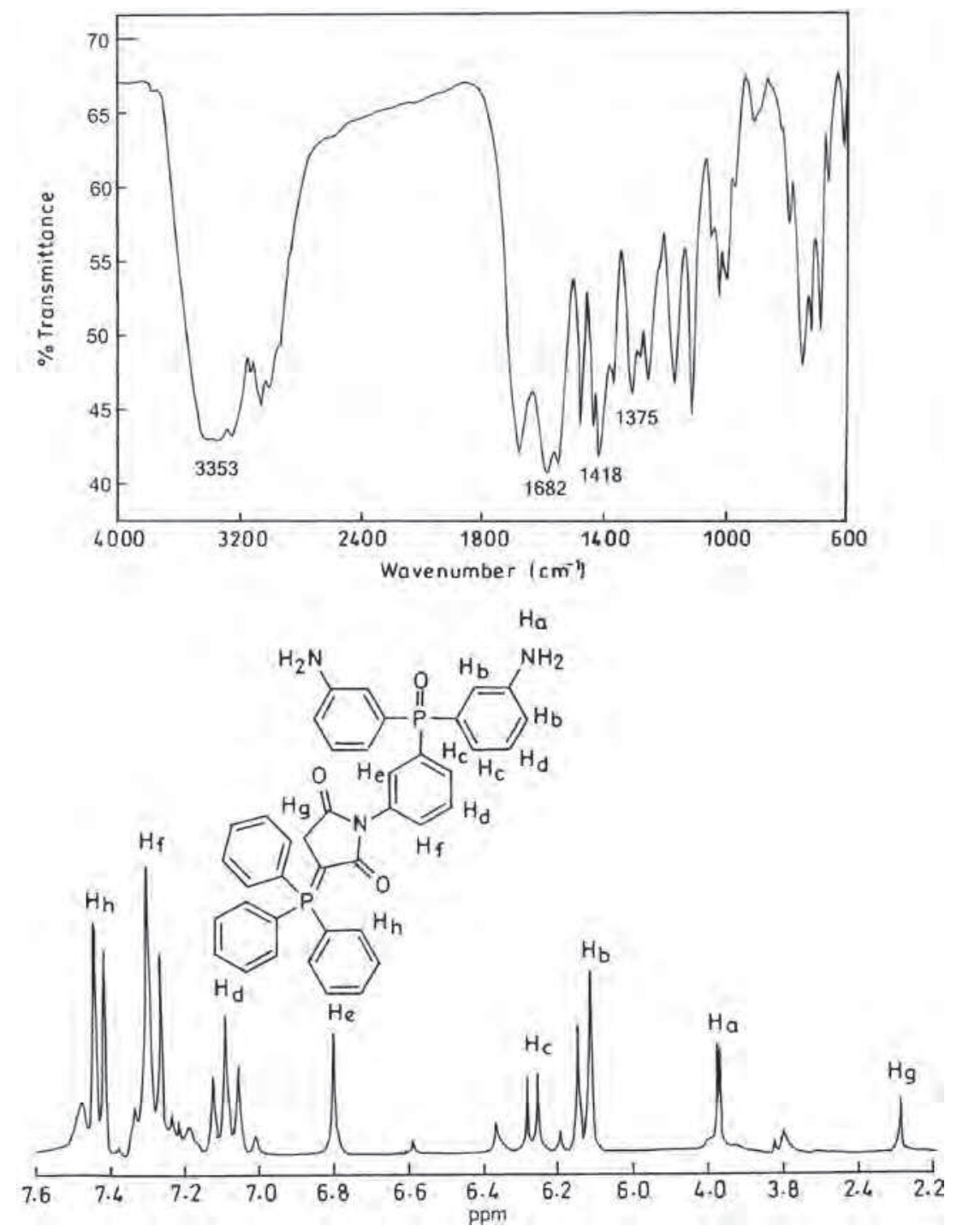

Figure 1. IR (top) and ${ }^{1} \mathrm{H}-\mathrm{NMR}$ (bottom) spectra of diamine, DA-1.

of TPP and pyridine as condensing agent outlined in scheme 3. All the poly(amide-imide)s are isolated as tough fibres in quantitative yield. The inherent viscosities values of resulting polymers in NMP at $25^{\circ} \mathrm{C}$ at a concentration of $0.5 \mathrm{~g} / \mathrm{dL}$ and GPC (gel permeation chromatography) analyses as well as elemental analyses are tabulated in table 3 . Inherent viscosities of polymers ranged from $0.64-0.78 \mathrm{dL} / \mathrm{g}$. The ratio of average molecular weights $(\mathrm{Mw} / \mathrm{Mn})$ of $\mathbf{5 c}$ and $\mathbf{5 d}$ found to be $23618 / 13731$ and $18236 / 9548$ respectively. The average molecular weights of polymer $5 \mathrm{a}$ and $5 \mathrm{~b}$ were not detectable due to their insolubility in THF. ${ }^{34}$ The tested values of elemental analysis of polymers generally agreed well with the theoretical values, as given in table 3 .

The structures of polymers are also confirmed by IR and ${ }^{1} \mathrm{H}-\mathrm{NMR}$ spectroscopy. IR spectrum of polymer, $\mathbf{5 b}$ is shown in figure 4 (top). This spectrum shows peak at $1774 \mathrm{~cm}^{-1}$ (imide carbonyl $\mathrm{C}=\mathrm{O}$ asymmetric stretching), at $1715 \mathrm{~cm}^{-1}$ (imide carbonyl $\mathrm{C}=\mathrm{O}$ asymmetric stretching), imide C-N stretching at $1383 \mathrm{~cm}^{-1}$, and those of amide group around $3397 \mathrm{~cm}^{-1}(\mathrm{~N}-\mathrm{H}$ stretching) and $1665 \mathrm{~cm}^{-1}(\mathrm{C}=\mathrm{O}$ stretching). Figure 4 (bottom), shows characteristic ${ }^{1} \mathrm{H}-\mathrm{NMR}$ spectrum of polymer, $\mathbf{5 b}$. The resonance signals of aromatic protons are appeared in the region 7.35-8.32 ppm. A sharp peak is observed due to $-\mathrm{NH}$ proton of pyrrole ring and a singlet due to secondary amide (-CONH) groups also observed at $8.58 \mathrm{ppm}$.

\subsection{Polymer properties}

3.3a Thermal analysis: All the aromatic poly (amide-imide)s exhibit good thermal stability and it is evaluated by thermogravimetric analysis (TGA) under 


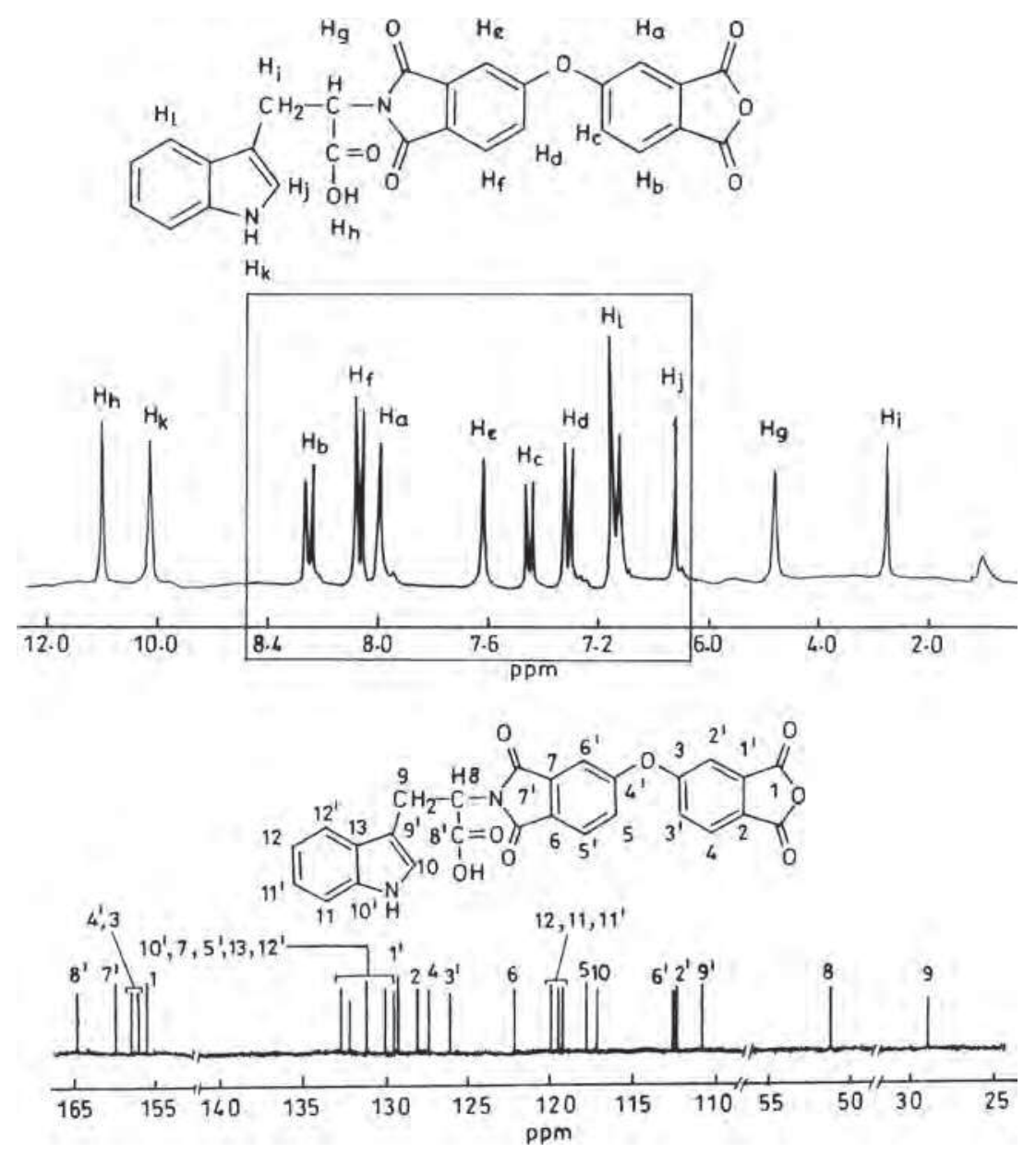

Figure 2. ${ }^{1} \mathrm{H}-\mathrm{NMR}$ (top) and ${ }^{13} \mathrm{C}-\mathrm{NMR}$ (bottom) spectra of monoanhydride, MA-2.

nitrogen atmosphere at the heating rate of $10^{\circ} \mathrm{C} / \mathrm{min}$ and all data are illustrated in table 4 . The initial decomposition temperature (IDT), as well as $5 \%$ and $10 \%$ weight loss $\left(\mathrm{T}_{\mathrm{d} 5 \%} \& \mathrm{~T}_{\mathrm{d} 10 \%}\right)$ are determined from TGA curve. The polymer exhibits almost one step decomposition pattern with no significant weight loss below $526^{\circ} \mathrm{C}$ and $10 \%$ weight loss values ranging $538^{\circ} \mathrm{C}$ to $583^{\circ} \mathrm{C}$. Among the polymers, BAP based poly(amideimide), $\mathbf{5 c}$ shows highest char yield i.e., $79 \%$ at $700^{\circ} \mathrm{C}$. The char yield of polymer, 5c can be explained by higher phosphorus content than other polymers $(68 \%$ char yield of $\mathbf{5 a}, 74 \%$ of $\mathbf{5 b}$ and $73 \%$ of $\mathbf{5 d}$ ), results in the formation of phosphorus rich residue from decomposition of isopropyl biphenyl phosphine moiety, which form a protecting layer on the surface of polymer and delay further decomposition. ${ }^{35,36}$

As shown in figure 5 (top), polymer $\mathbf{5 d}$, containing trifluoromethyl groups has the highest thermal stability. Obviously, the incorporation of trifluoromethyl groups into side chain of the polymer enhances the thermal stability. DDS based polymer, 5b also exhibits high initial decomposition temperature but slightly lower than the polymer, 5d. On the other hand, the amount of carbonized weight residue (char yield) of polymer, $5 \mathbf{b}$ is almost higher than fluorine based polymer.

However polymer, 5a exhibits much lower initial decomposition temperature, faster degradation behaviour around $600^{\circ} \mathrm{C}$ and lower char yield at $700^{\circ} \mathrm{C}$ than the other polymers. The low thermal stability can be explained by poor thermal stability of ether linkage in polymeric chain. ${ }^{37}$ Obviously, the data from thermal analysis shows that these poly(amide-imide)s have fairly high thermal stability due to presence of very rigid aromatic heterocyclic backbone. The high char yield of the polymers can be ascribed to their high aromatic content in the polymeric chain. ${ }^{38}$

3.3b DSC measurements: The glass transition temperature $\left(\mathrm{T}_{\mathrm{g}}\right)$ of polymers is evaluated by differential scanning calorimetry (DSC) under nitrogen atmosphere at the heating rate of $10^{\circ} \mathrm{C} / \mathrm{min}$ and characteristic data are summarized in table 4 . Hereby, $\mathrm{T}_{\mathrm{o}}$ (the onset temperature, defines the point at which the first deviation from baseline on the low temperature side of a DSC curve is observed) and $\mathrm{T}_{\mathrm{g}}$ (the mid-point temperature of baseline shift) values of the resulting polymers are 


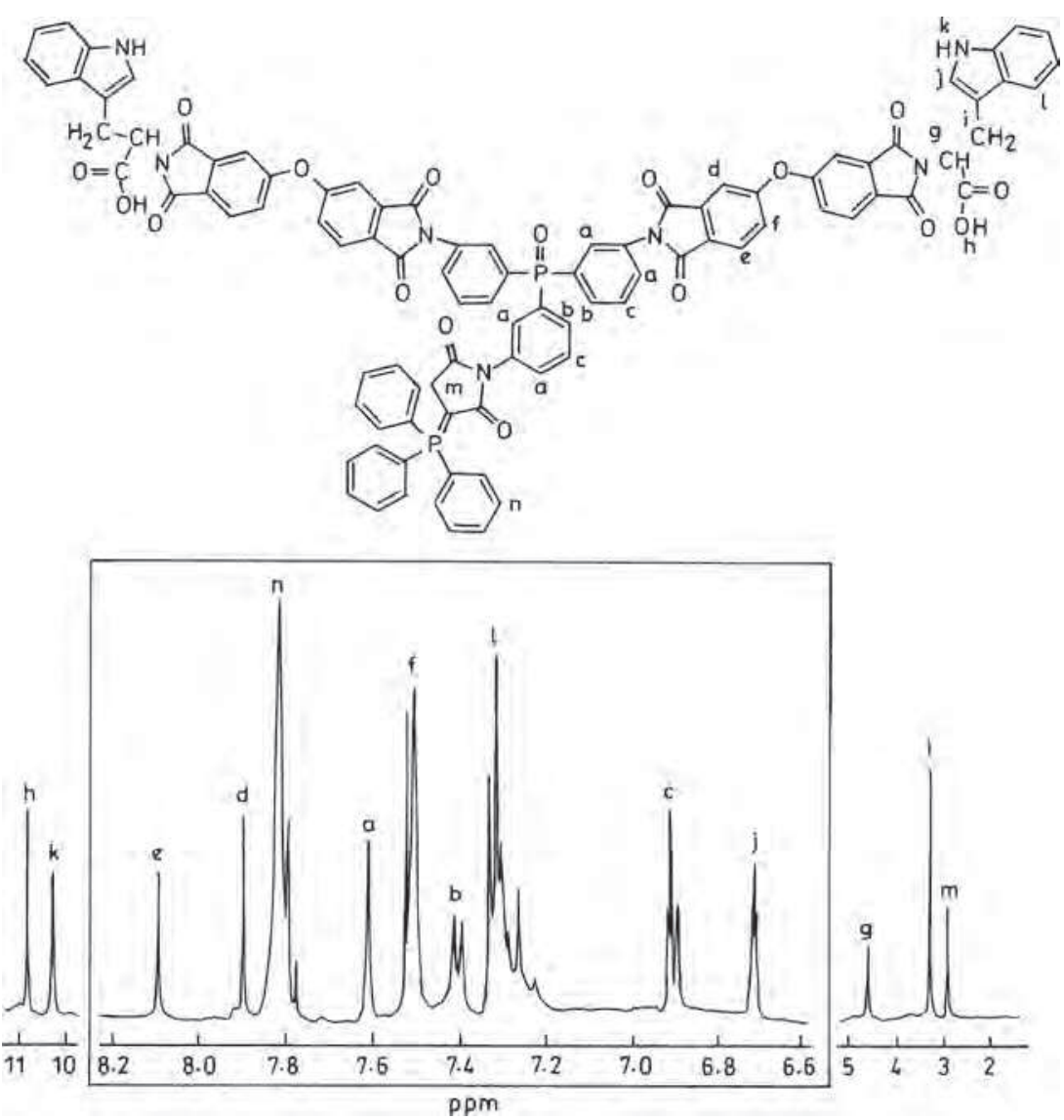

Figure 3. ${ }^{1} \mathrm{H}-\mathrm{NMR}$ spectrum of dicarboxylic acid, DCA-3.

determined. A typical DSC thermogram of polymer, 5d is shown in figure 5 (bottom), and the $\mathrm{T}_{\mathrm{g}}$ values of all polymer, 5a-d are found in the range $271-346^{\circ} \mathrm{C}$. As anticipated, the $\mathrm{T}_{\mathrm{g}}$ values depend on the structure of the diamine component. ${ }^{39}$

In general, the chain rigidity increases due to the incorporated groups, which restricts the free rotation of the polymer backbone. Fluorine based polymer shows higher $\mathrm{T}_{\mathrm{g}}$ than other polymers which can be attributed to the increased rotational barrier caused by the $-\mathrm{CF}_{3}$ substituents in diamine BAF. Among the polymers, BAP based polymer shows lower $\mathrm{T}_{\mathrm{g}}$ value, due to high phosphorus content. In addition to DCA-3, the values of $\mathrm{T}_{\mathrm{g}}$ are normally affected by diamine moieties too, which shows the order $\mathbf{5 b}>\mathbf{5 d}>\mathbf{5} \mathbf{a}>\mathbf{5} \mathbf{c}$ as illustrated in table 4 . The $\mathrm{T}_{\mathrm{g}}$ values of polymer, $\mathbf{5} \mathbf{a}$ is less than $\mathbf{5 b}$ and $\mathbf{5 d}$ because of the presence of ether linkage. ${ }^{40}$ As the chain rigidity increases due to incorporated groups, it restricts the free rotation of polymer, $\mathbf{5 a}$ and $\mathbf{5 b}$ backbone.

3.3c Solubility of poly(amide-imide)s in organic solvents: The solubility of all aromatic polymers is determined qualitatively in various organic solvents and results are tabulated in table 5. Remarkably, all these polymers exhibit excellent solubility in polar aprotic solvents such as NMP, DMSO, DMF, DMAc and slightly soluble in less polar solvents like m-cresol and pyridine. Polymers $\mathbf{5 c}$ and $\mathbf{5 d}$ are also soluble in common organic solvents such as chloroform and THF.

The excellent solubility of these polymers may be attributed to the presence of twist and non-coplaner aromatic heterocyclic moiety in the polymer backbone, decrease the intermolecular force between polymeric chains and inhibits the dense packing of the polymer chains. ${ }^{41}$ The solubility of polymer is greatly enhanced by the incorporation of phosphine oxide moiety and further by bulky $-\mathrm{CF}_{3}$ groups, biphenyl phosphorus moiety and more flexible ether group are especially effective for high solubility. ${ }^{36}$ The $-\mathrm{CF}_{3}$ groups in polymer, $\mathbf{5 d}$ increase its solubility in organic solvents relative to other polymers due to combination of steric and electronic effects. Presence of these bulky $-\mathrm{CF}_{3}$ groups in polymer increase free volume, endow a large amount of polarity due to the high electronegativity of $\mathrm{F}$ atoms and thereby this polymer shows excellent organosolubility. ${ }^{40}$ Polymer, $5 \mathbf{c}$ caused by entropy advantages resulted from the laterally attached bulky biphenyl phosphine group that inhibits the close packing of the polymeric chain. However, polymer, $\mathbf{5 b}$ is insoluble in 
Table 2. FT-IR, ${ }^{1} \mathrm{H}-\mathrm{NMR},{ }^{13} \mathrm{C}-\mathrm{NMR}$ and ${ }^{31} \mathrm{P}-\mathrm{NMR}$ Spectral characterization data of intermediate compounds and monomer.

\begin{tabular}{|c|c|c|c|c|}
\hline Monomer & $\mathrm{IR}\left(\mathrm{KBr}, \mathrm{cm}^{-1}\right)$ & ${ }^{1} \mathrm{H}-\mathrm{NMR}\left(\mathrm{DMSO}-d_{6}, \delta \mathrm{ppm}\right)$ & ${ }^{13} \mathrm{C}-\mathrm{NMR}\left(\mathrm{DMSO}-d_{6}, \delta \mathrm{ppm}\right)$ & ${ }^{31} \mathrm{P}-\mathrm{NMR}\left(\mathrm{DMSO}-d_{6}, \delta \mathrm{ppm}\right)$ \\
\hline DA-1 & $\begin{array}{c}\text { 3,353 (amine } \mathrm{N}-\mathrm{H} \text { str) } \\
1,682 \text { (amide } \mathrm{C}=\mathrm{O} \text { str) } \\
1,418(\mathrm{P}-\mathrm{Ar} \text { str) } \\
1,195(\mathrm{P}=\mathrm{O} \text { str) } \\
1,375 \text { (imide } \mathrm{C}-\mathrm{N} \text { str) }\end{array}$ & $\begin{array}{c}2.29\left(\mathrm{~s}, 1 \mathrm{H},-\mathrm{CH}_{2}\right), 3.97(\mathrm{~s} \\
\left.2 \mathrm{H},-\mathrm{NH}_{2}\right), 6.15(\mathrm{~d}, 1 \mathrm{H}, \mathrm{Ar}-\mathrm{H}) \\
6.28(\mathrm{~d}, 1 \mathrm{H}, \mathrm{Ar}-\mathrm{H}), 6.81(\mathrm{~s} \\
1 \mathrm{H}, \mathrm{Ar}-\mathrm{H}), 7.12(\mathrm{t}, 1 \mathrm{H}, \mathrm{Ar}-\mathrm{H}) \\
7.33(\mathrm{~d}, 1 \mathrm{H}, \mathrm{Ar}-\mathrm{H}), 7.42(\mathrm{~m}, \\
\text { 1H,Ar-H), }\end{array}$ & $\begin{array}{c}162.6,155.6,139.2,138.9 \\
132.6,131.3,128.8,127.9 \\
127.4,126.6,124.8,122.6 \\
121.1,119.8,117.3,15.9\end{array}$ & -25.36 \\
\hline MA-2 & $\begin{array}{c}\text { 3,215 (O-H str) } \\
1,380 \text { (imide C-N str) } \\
1,678 \text { (amide } \mathrm{N}-\mathrm{H} \text { str) } \\
2928\left(\mathrm{C}-\mathrm{H} \text { str of }-\mathrm{CH}_{2}\right)\end{array}$ & $\begin{array}{c}2.86\left(\mathrm{~d}, 2 \mathrm{H},-\mathrm{CH}_{2}\right), 4.76(\mathrm{t}, \\
1 \mathrm{H},-\mathrm{CH}-), 6.83(\mathrm{~s}, 1 \mathrm{H},-\mathrm{CH}-), \\
7.16(\mathrm{~m}, 1 \mathrm{H}, \mathrm{Ar}-\mathrm{H}), 7.33(\mathrm{~d}, 1 \mathrm{H}, \\
\mathrm{Ar}-\mathrm{H}), 7.46(\mathrm{~d}, 1 \mathrm{H}, \mathrm{Ar}-\mathrm{H}), 7.62 \\
(\mathrm{~s}, 1 \mathrm{H}, \mathrm{Ar}-\mathrm{H}), 7.98(\mathrm{~s}, 1 \mathrm{H}, \mathrm{Ar}-\mathrm{H}) \\
8.08(\mathrm{~d}, 1 \mathrm{H}, \mathrm{Ar}-\mathrm{H}), 8.27(\mathrm{~d}, 1 \mathrm{H}, \mathrm{Ar}-\mathrm{H}), \\
10.2(\mathrm{~s}, 1 \mathrm{H},-\mathrm{NH}-), 11.1(\mathrm{~s}, 1 \mathrm{H},-\mathrm{COOH})\end{array}$ & $\begin{array}{c}165.1,161.2,158.2,157.6 \\
156.8,132.8,132.6,131.4 \\
130.6,129.7,129.3,128.1 \\
127.3,126.5,122.1,119.8 \\
119.1,118.9,118.6,117.4 \\
\begin{array}{c}113.2,112.3,111.2,51.2 \\
29.6\end{array}\end{array}$ & - \\
\hline DCA-3 & $\begin{array}{c}\text { 3,265 (O-H str), 1,115 } \\
\text { (C-O-C str), 1,194 (P=O str), } \\
1,426 \text { (P-Ar str), } 1,779 \text { (imide } \\
\mathrm{C}=\mathrm{O} \text { asymmetric str), 1,719 } \\
\text { (imide } \mathrm{C}=\mathrm{O} \text { symmetric str), } \\
\text { 1,661 (amide N-H str), 1,370 } \\
\quad \text { (imide C-N str) }\end{array}$ & $\begin{array}{c}2.92\left(\mathrm{~s}, 2 \mathrm{H},-\mathrm{CH}_{2}\right), 3.18(\mathrm{~d}, \\
\left.2 \mathrm{H},,-\mathrm{CH}_{2}\right), 4.63(\mathrm{t}, 1 \mathrm{H},-\mathrm{CH}-) \\
6.74(\mathrm{~s}, 1 \mathrm{H},-\mathrm{CH}-), 6.92(\mathrm{t}, 1 \mathrm{H}, \\
\text { Ar-H), } 7.34(\mathrm{~m}, 1 \mathrm{H}, \mathrm{Ar}-\mathrm{H}), 7.42(\mathrm{~d}, \\
\text { 1H,Ar-H), } 7.61(\mathrm{~s}, 1 \mathrm{H}, \mathrm{Ar}-\mathrm{H}), \\
7.82(\mathrm{~m}, 1 \mathrm{H}, \mathrm{Ar}-\mathrm{H}), 7.91(\mathrm{~s}, 1 \mathrm{H}, \\
\text { Ar-H), } 8.09(\mathrm{~s}, 1 \mathrm{H}, \mathrm{Ar}-\mathrm{H}), 10.31 \\
\text { (s, N-H proton), 10.93 (s, 1H,-COOH) }\end{array}$ & $\begin{array}{l}\text { 175.2, 164.8, 163.7, 162.6, } \\
\text { 160.8, 158.2 139.6, 139.1, } \\
\text { 136.7, 134.6, 131.8, 130.9, } \\
\text { 129.2, 128.2, 127.9, 127.3, } \\
\text { 126.1, 125.8, 122.9, 122.8, } \\
\text { 121.7, 121.4, 121.2, 120.9, } \\
\text { 120.4, 119.9, 118.7, 115.6, } \\
111.6,110.7,51.8,28.7,16.1\end{array}$ & $-18.83,-26.82$ \\
\hline
\end{tabular}


Table 3. Inherent viscosities and elemental analysis of poly(amide-imide)s.

\begin{tabular}{|c|c|c|c|c|c|c|c|c|}
\hline Polymer & $\begin{array}{c}\eta_{\text {inh }} \\
(\mathrm{dL} / \mathrm{g})^{\mathrm{a}}\end{array}$ & $\mathrm{Mw} / \mathrm{Mn}^{\mathrm{b}}$ & $\mathrm{PDI}^{\mathrm{c}}$ & Closed Formula & Elemental & Analysis C (\%) & $\mathrm{H}(\%)$ & $\mathrm{N}(\%)$ \\
\hline $5 \mathrm{a}$ & 0.76 & $-\mathrm{d}$ & $-{ }^{d}$ & $\left(\mathrm{C}_{111} \mathrm{H}_{81} \mathrm{~N}_{9} \mathrm{O}_{16} \mathrm{P}_{2}\right)_{\mathrm{n}}$ & Calcd. Found & 71.7271 .48 & 4.394 .54 & 6.786 .90 \\
\hline $5 b$ & 0.78 & $-\mathrm{d}$ & $-\mathrm{d}$ & $\left(\mathrm{C}_{111} \mathrm{H}_{81} \mathrm{~N}_{9} \mathrm{O}_{17} \mathrm{P}_{2} \mathrm{~S}\right)_{\mathrm{n}}$ & Calcd. Found & 69.9169 .47 & 4.284 .03 & 6.616 .29 \\
\hline $5 \mathrm{c}$ & 0.69 & $23618 / 13731$ & 1.72 & $\left(\mathrm{C}_{114} \mathrm{H}_{88} \mathrm{~N}_{9} \mathrm{O}_{15} \mathrm{P}_{3}\right)_{n}$ & Calcd. Found & 71.4371 .68 & 4.634 .29 & 6.586 .70 \\
\hline $5 \mathrm{~d}$ & 0.64 & $18236 / 9548$ & 1.91 & $\begin{array}{c}\left(\mathrm{C}_{114} \mathrm{H}_{81} \mathrm{~F}_{6} \mathrm{~N}_{9} \mathrm{O}_{15} \mathrm{P}_{2}\right)_{n} \\
(1992.85)_{n}\end{array}$ & Calcd. Found & 68.7168 .48 & 4.103 .87 & 6.335 .98 \\
\hline
\end{tabular}

${ }^{a}$ Measured in NMP at $25^{\circ} \mathrm{C}$ at a concentration of $0.5 \mathrm{~g} / \mathrm{dL}$

${ }^{\mathrm{b}}$ Measured by GPC in THF with polystyrene as a standard

cPolydispersity index

${ }^{\mathrm{d}}$ Polymer was insoluble in THF at room temperature
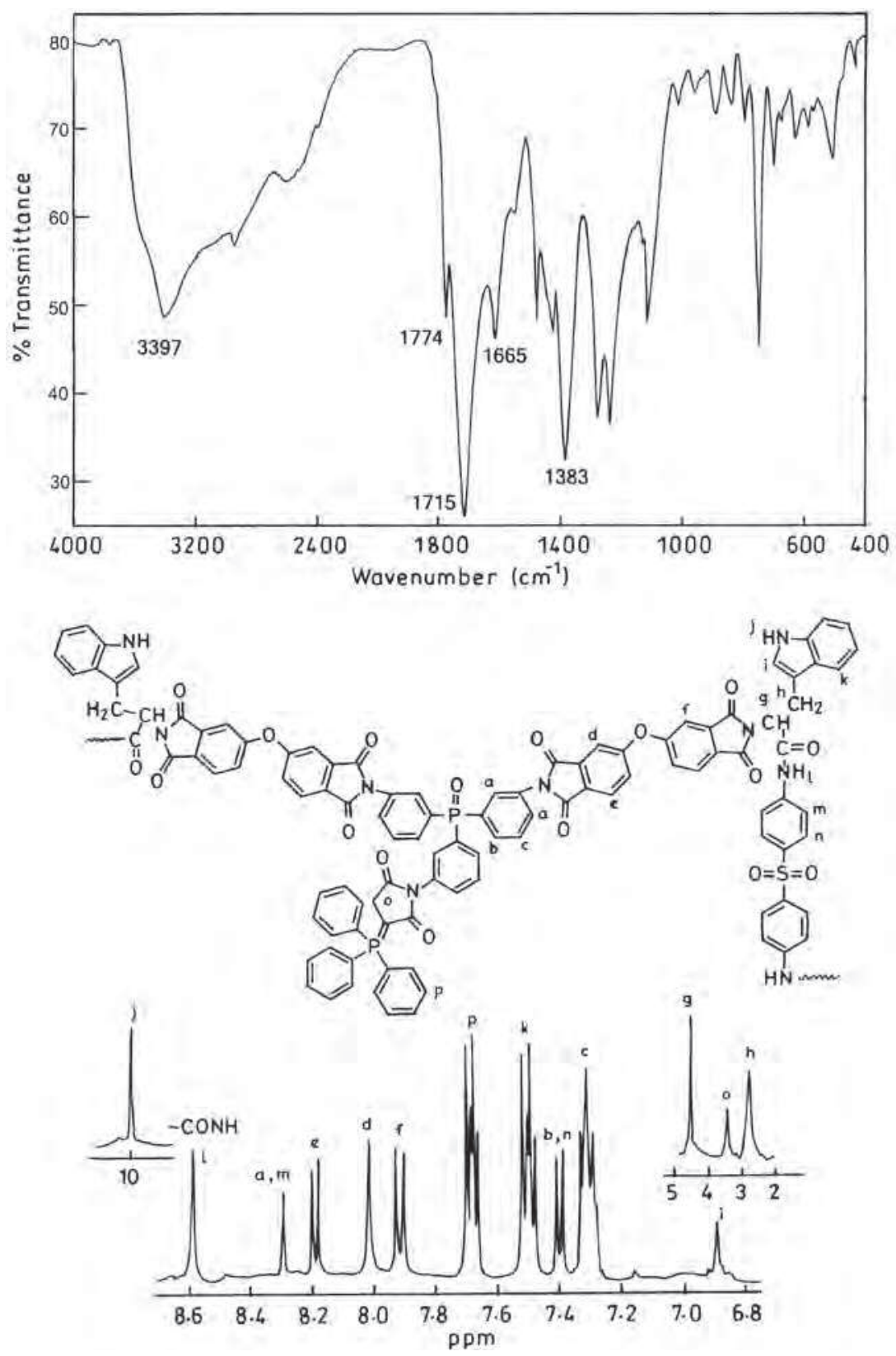

Figure 4. IR (top) and ${ }^{1} \mathrm{H}-\mathrm{NMR}$ (bottom) spectra of polymer, $5 \mathrm{~b}$. 
Table 4. Thermal properties of poly(amide-imide)s.

\begin{tabular}{lccccc}
\hline Polymer & $\begin{array}{c}\mathrm{IDT}^{\mathrm{a}} \\
\left({ }^{\circ} \mathrm{C}\right)\end{array}$ & $\begin{array}{c}\mathrm{T}_{\mathrm{d} 10 \%}^{\mathrm{b}} \\
\left({ }^{\circ} \mathrm{C}\right)\end{array}$ & $\begin{array}{c}\text { Char } \\
\text { Yield }(\%)\end{array}$ & $\begin{array}{c}\mathrm{T}_{\mathrm{o}}^{\mathrm{d}} \\
\left({ }^{\circ} \mathrm{C}\right)\end{array}$ & $\begin{array}{c}\mathrm{T}_{\mathrm{g}}^{\mathrm{e}} \\
\left({ }^{\circ} \mathrm{C}\right)\end{array}$ \\
\hline $5 \mathrm{a}$ & 526 & 538 & 68 & 284 & 298 \\
$5 \mathrm{~b}$ & 560 & 579 & 74 & 338 & 346 \\
$5 \mathrm{c}$ & 548 & 566 & 79 & 259 & 257 \\
$5 \mathrm{~d}$ & 562 & 583 & 73 & 317 & 328 \\
\hline
\end{tabular}

anitial decomposition temperature, determined by TGA in $\mathrm{N}_{2}$ atmosphere at a heating rate of $10^{\circ} \mathrm{C} / \mathrm{min}$

${ }^{\mathrm{b}}$ Temperature of $10 \%$ weight loss, determined by TGA in $\mathrm{N}_{2}$ atmosphere at a heating rate of $10^{\circ} \mathrm{C} / \mathrm{min}$

${ }^{c}$ Residual weight $\%$ at $700^{\circ} \mathrm{C}$ in nitrogen

${ }^{\mathrm{d}}$ Onset temperature from DSC measurements in $\mathrm{N}_{2}$, defines the point at which the first deviation from the baseline on the low temperature side is observed

${ }^{\mathrm{e}}$ Glass transition temperatures from the DSC traces in $\mathrm{N}_{2}$ at heating rate of $10^{\circ} \mathrm{C} / \mathrm{min}$
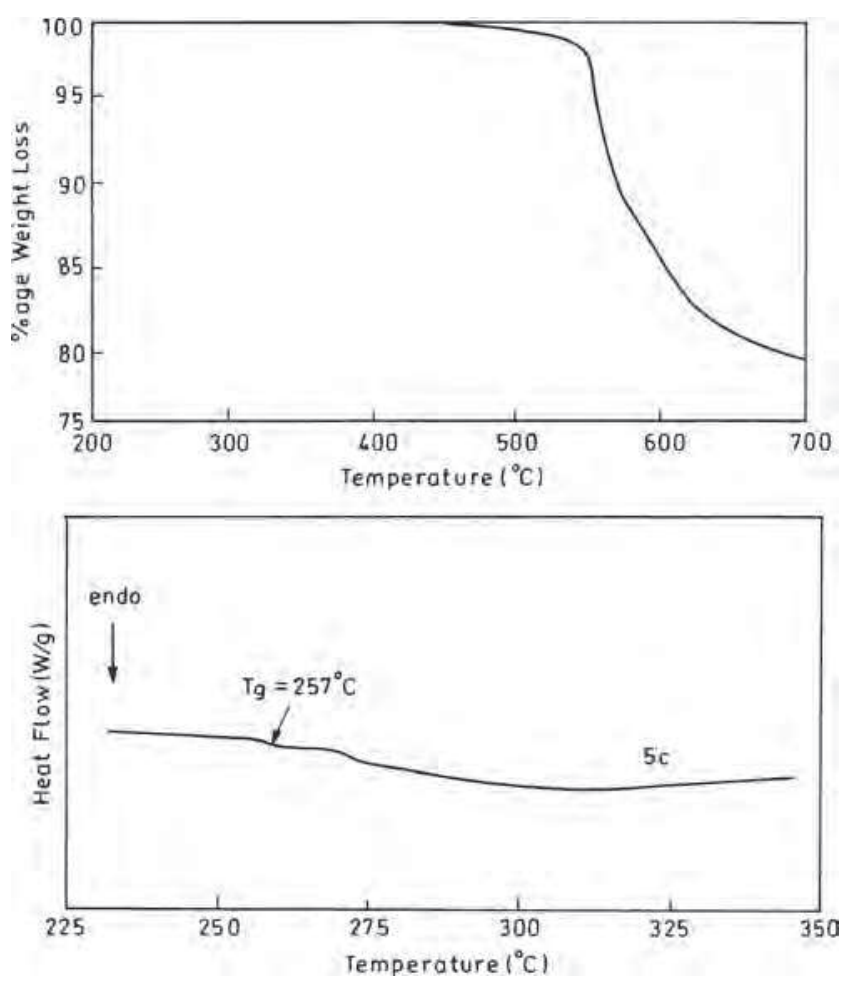

Figure 5. TGA (top) and DSC (bottom) thermograms of polymer, 5c.

chloroform and THF, owing to the rigid structure of DDS.

3.3d XRD studies: The crystallinity of polymers is evaluated by wide angle $\mathrm{X}$-ray diffraction experiment at room temperature. The wide angle X-ray diffractograms shows that the polymer films are essentially amorphous. The amorphous behaviour of the
Table 5. Solubility of poly(amide-imide)s in organic solvents.

\begin{tabular}{lcccc}
\hline & Polymer, & Polymer, & Polymer, & Polymer, \\
Solvent & $5 \mathrm{a}$ & $5 \mathrm{~b}$ & $5 \mathrm{c}$ & $5 \mathrm{~d}$ \\
\hline $\mathrm{NMP}$ & ++ & ++ & ++ & ++ \\
DMF & ++ & ++ & ++ & ++ \\
DMSO & ++ & ++ & ++ & ++ \\
DMAc & ++ & ++ & ++ & ++ \\
THF & + & - & ++ & ++ \\
m-cresol $_{\mathrm{H}_{2} \mathrm{SO}_{4}}$ & + & + & ++ & ++ \\
Pyridine & ++ & ++ & ++ & ++ \\
Chloroform & + & + & + & + \\
Acetone & + & - & ++ & ++ \\
& + & - & + & + \\
\hline
\end{tabular}

++ Highly soluble, + Sparingly soluble, - Insoluble DMF : N,N-dimethyl formamide, THF: tetrahydrofuran, DMSO: dimethyl sulphoxide, NMP:N-methyl-2-pyrrolidone, $\mathrm{H}_{2} \mathrm{SO}_{4}$ : sulphuric acid, DMAc:N,N-dimethyl acetamide

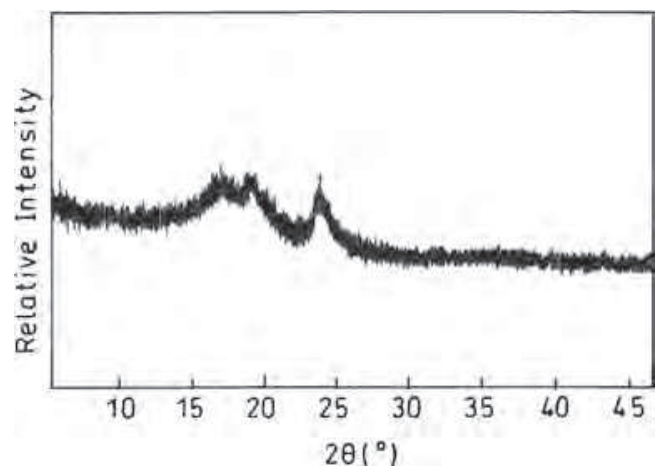

Figure 6. Wide-angle X-ray diffractogram of polymer, 5a.

polymers can be attributed to the structural modification through the incorporation of the non-coplaner triphenyl phosphine moiety. The presence of triphenyl phosphine and non-coplaner amines might decrease the intermolecular forces between the polymeric chains due to loose packing as compared to the unsubstituted polymer. Therefore, crystallization tendency is markedly lowered and the solubilities are significantly enhanced. A wide angle diffractogram of polymer, 5a is shown in figure 6.

3.3e Optical properties: The optical properties of the PAIs films are evaluated by UV-Vis spectroscopy. Cut off wavelength $\left(\lambda_{0}\right.$, is defined as the mid-point at which the transmittance from the prepared thin films becomes less than 1\%) and $80 \%$ transmission wavelength $\left(\lambda_{80 \%}\right.$, is defined as the mid-point at which the light transmittance from the films becomes less than $80 \%$ and this mid-point lies at the left side of plateau region in the UV-Vis absorption spectrum) for PAIs 
Table 6. Film characteristics and optical properties of resulting poly(amide-imide)s.

\begin{tabular}{lcccc}
\hline Polymer & $\lambda_{\max }^{\mathrm{a}}(\mathrm{nm})$ & $\lambda_{\mathrm{o}}^{\mathrm{b}}(\mathrm{nm})$ & $\lambda_{80 \%}^{\mathrm{c}}(\mathrm{nm})$ & Film quality $^{\mathrm{d}}$ \\
\hline $5 \mathrm{a}$ & 278 & 369 & 541 & Transparent, Flexible \\
$5 \mathrm{~b}$ & 269 & 373 & 552 & Transparent, Flexible \\
$5 \mathrm{c}$ & 290 & 368 & 544 & Opaque, Flexible \\
$5 \mathrm{~d}$ & 265 & 362 & 540 & Transparent, Flexible
\end{tabular}

${ }^{\mathrm{a} O b t a i n e d ~ f r o m ~ t h e ~ d i l u t e d ~ s o l u t i o n s ~ w i t h ~ p o l y m e r ~ c o n c e n t r a t i o n ~ o f ~}$ $10^{-5} \mathrm{~mol} / \mathrm{L}$ in DMSO

${ }^{\mathrm{b}} \mathrm{Cut}$ off wavelength at which the light transmittance from thin film becomes below $1 \%$

${ }^{c}$ Wavelength at which the light transmittance from thin film becomes below $0 \%$

${ }^{\mathrm{d}}$ Films were casted by slow evaporation of polymer solution in DMSO

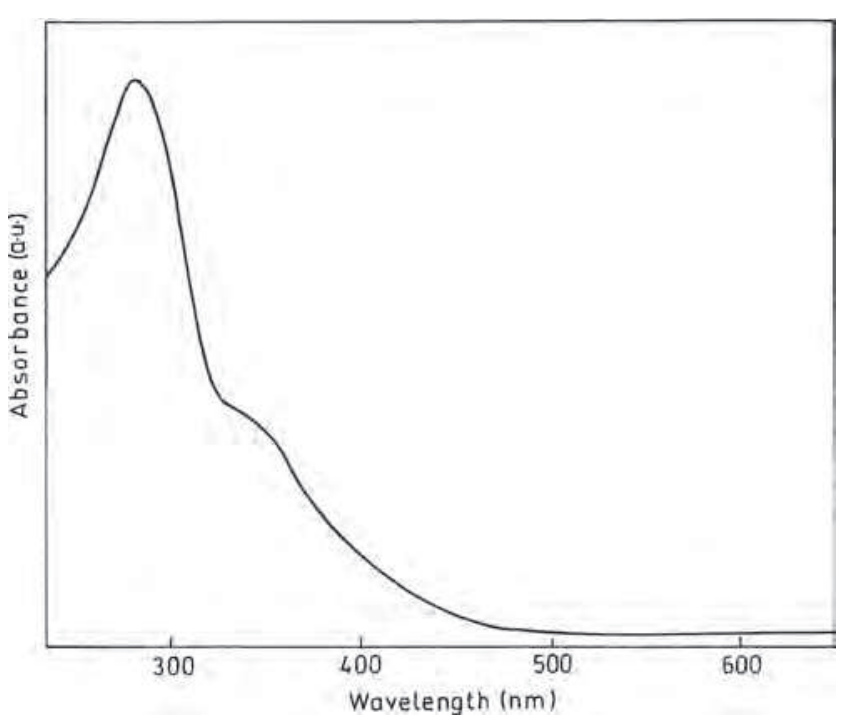

Figure 7. UV-Vis absorption spectrum of polymer, $5 \mathrm{~d}$.

films are investigated and listed in table 6 . These polymers exhibit $\lambda_{80 \%}$ in the range $540-552 \mathrm{~nm}$ and their $\lambda_{\mathrm{o}}$ in between $362-373 \mathrm{~nm}$, which revealed that the polymers are low coloured with high transparency in visible light region. It is observed that the $\lambda_{80 \%}$ and $\lambda_{0}$ of polymer, $\mathbf{5 d}$ are lower than that of analogous polymers. Thereby polymer, 5d shows excellent optical properties compared to other polymers, which is attributed to the trifluoromethyl groups in the polymeric side chain, resulting in the reduction of the intramolecular conjugation and prevents the extensive electronic conjugation. ${ }^{42}$

In addition, the $\lambda_{80 \%}$ and $\lambda_{o}$ for $\mathbf{5 a}, \mathbf{5 b}$ and $\mathbf{5 c}$ polymeric films are much longer than those of the corresponding polymer, $\mathbf{5 d}$. This indicates that ether group in $\mathbf{5 a}$, DDS in $\mathbf{5 b}$ and biphenyl phosphine group in $\mathbf{5 c}$, are not efficient in breaking the conjugation length as trifluoromethyl group in $\mathbf{5 d}$. This is probably because of the differences in both their electronic states in conjugation with the polymeric chain. The UV-Vis absorption spectrum of polymer, $\mathbf{5 d}$ is shown in figure 7 .

\section{Conclusions}

Four poly(amide-imide)s were synthesized by the reaction of a new aromatic dicarboxylic acid having triphenyl phosphine oxide moiety with different aromatic diamines. The incorporation of triphenyl phosphine oxide and oxyphenyl groups in main chain of polymers modify largely the properties of polymers. All the lowcoloured polymer films show high optical transparency in visible region and are highly flexible. The synthesized polymers still maintain excellent thermal stability and reasonable glass transition temperatures $\left(\mathrm{T}_{\mathrm{g}} \mathrm{s}\right)$ suitable for thermoforming processing. Moreover, the resulting polymers display low crystallinity and good film forming capability.

\section{Supplementary Information}

Supplementary information contains elementary data of polymer 5a, 5b, 5c and 5d. GPC data of polymer $5 \mathrm{c},{ }^{1} \mathrm{H}-$ NMR spectra of polymer $5 \mathrm{a}, 5 \mathrm{c}$ and $5 \mathrm{~d}$ and is available at www.ias.ac.in/chemsci.

\section{Acknowledgements}

The author (S. Agrawal) is grateful to Guru Gobind Singh Indraprastha University, New Delhi for providing financial support in the form of IPRF.

\section{References}

1. Li P, Rehman S, Zhou H W, Zhao X G, Dang G D and Chen C H 2012 Polym. Degrad. Stabil. 971581 
2. Park S, Kim K, Kim J C, Kwon W, Kim D M and Ree M 2011 Polymer 522170

3. Kim K, Yen H-J, Ko Y-G, Chang C-W, Kwon W, Liou G-S and Ree M 2012 Polymer 534135

4. Wu Z, Han B, Zhang C, Zhu D, Gao L, Ding M and Yang Z 2012 Polymer 535706

5. Cakmakcl E Gungor A Polym. Degrad. Stabil. 98927

6. Grucela-Zajac M, Filapek M, Skorka L, Gasiorowski J, Glowacki E D, Neugebauer H and Schab-Balcerzak E 2012 Mater. Chem. Phys. 137221

7. Qi H, Liu F, Zhang N, Chen Y, Yang H and Wang Z 2012 Prog. Org. Coat. 7333

8. Wang C-S and Leu T-S 2000 Polymer 413581

9. Liaw D-J, Liaw B-Y and Yu C-W 2001 Polymer 425175

10. Lin C H, Chang S L, Peng L A, Peng S P and Chuang Y H 2010 Polymer 513899

11. Zhao X, Geng Q-F, Zhou T-H, Gao X-H and Liu G 2013 Chin. Chem. Let. 2431

12. Behniafar H, Beit-Saeed A and Hadian A 2009 Polym. Degrad. Stabil. 941991

13. Sadavarte N V, Avadhani C V, Naik P V and Wadgaonkar P P 2010 Eur. Polym. J. 461307

14. Dasgupta B and Banerjee S 2010 J. Memb. Sci. 36258

15. Ghaemy M, Alizadeh R and Behmadi H 2009 Eur. Polym. J. 453108

16. Bazzar M, Ghaemy M and Alizadeh R 2013 React. Funct. Polym. 73492

17. Zamanloo M R, Shamkhali A N, Alizadeh M, Mansoori Y and Imanzadeh G 2012 Dyes Pigm. 95 587

18. Hamciuc E, Hamciuc C, Sava I and Bruma M 2001 Eur. Polym. J. 37287

19. Faghihi K and Hagibeygi M 2003 Eur. Polym. J. 39 2307

20. Abid S, Gharbi R E and Gandini A 2004 Polymer 45 6469

21. Wang X L, Li Y F, Ma T, Zhang S J and Gong C L 2006 Polymer 473774

22. Liu J G, He M H, Qian Z G and Yang S Y 2002 Polym. Sci. Part A: Polym. Chem. 401572
23. Shi Z M, Hasegawa M and Shindo Y 2000 High Perform. Polym. 12377

24. Behniafar H and Mohammadparast-Delshaad S 2012 Polym. Degrad. Stabil. 97228

25. Mallakpour S and Rafiemanzelat F 2005 React. Funct. Polym. 62153

26. Liaw D-J, Wang K-L, Huang Y-C, Lee K-R, Lai J-Y and Ha C-S 2012 Prog. Polym. Sci. 37907

27. Yang C-P and Su Y-Y 2005 Polymer 465797

28. Dhara M G and Banerjee S 2010 Prog. Polym. Sci. 35 1022

29. Brink M H, Brandom D K, Wilkes G L and McGrath J E 1994 Polymer 355018

30. Yamazaki N, Matsumoto M and Higashi F $1975 \mathrm{~J}$. Polym. Sci.: Polym. Chem. 131373

31. Levchik S V, Costa L and Camino G 1992 Polym. Degrad. Stabil. 36229

32. Levchik S V, Costa L and Camino G 1994 Polym. Degrad. Stabil. 4343

33. Khurana P, Aggarwal S, Narula A K and Choudhary V 2003 J. Appl. Polym. Sci. 871345

34. Liu C, Li X, Xu J and Jian X 2011 Eur. Polym. J. 47 1852

35. Wang S, Ji Q, Tchatchoua C N, Shultz A R and Mc Grath J E 1999 J. Polym.Sci. Part B: Polym. Phys. 37 1849

36. Jeong K U, Kim J-J and Yoon T-H 2001 Polymer 42 6019

37. Bu Q, Zhang S, Li H, Li Y, Gong C and Yang F 2011 Polym. Degrad. Stabil. 961911

38. Liu C, Wang J, Lin E, Zong L and Jian X 2012 Polym. Degrad. Stabil. 97460

39. Shockravi A, Abouzari-Lotf E, Javadi A and Atabaki F 2009 Eur. Polym. J. 451599

40. Zhang S-J, Bu Q-Q, Li Y-F, Gong C-L, Xu X-Y and Li H 2011 Mater. Chem. Phys. 128392

41. Cheng L and Jian X G 2004 J. Appl. Polym. Sci. 92 1516

42. Tao L, Yang H, Liu J, Fan L and Yang S 2009 Polymer 506009 